\title{
Two intersex dogs with mosaicism
}

\author{
Anne R. Dain and R. G. Walker \\ A.R.C. Institute of Animal Physiology, Babraham, Cambridge CB2 4AT and \\ Department of Clinical Veterinary Medicine, University of Cambridge, Madingley Road, \\ Cambridge CB3 OES, U.K.
}

\begin{abstract}
Summary. Two intersex dogs with various degrees of mosaicism in the somatic tissues are described. Normal female cells as well as Y-bearing cells with aneuploidy and other abnormalities were involved. In the Red setter an ovarian cortex had developed in mosaic gonads with 8 and $10 \%$ of Y-bearing cells. Slight masculinization of the medullae corresponded with some external virilization. These observations support the existence of a threshold proportion of $\mathrm{Y}$-bearing cells for testicular differentiation. Fragments of chromatin in $36 \%$ or fewer of the cells in the Cocker spaniel may have been translocated $\mathrm{Y}$-chromosome material.
\end{abstract}

\section{Introduction}

Intersex conditions in the dog have been described on many occasions. A brief review of cases of known and unknown genetic sex has been given (Dain, 1974). The anatomy and cytogenetics of an intersex Red setter and a Cocker spaniel are given in this paper.

\section{Materials and Methods}

Both dogs were pets which were brought for treatment to the Hospital at the School of Veterinary Medicine, Cambridge.

Chromosome spreads were made from cultures of blood lymphocytes in whole blood by a modification of the method of Basrur \& Gilman (1964). Cell cultures of the other organs were made by a modification of the method of Tucker, Dain \& Moor (1978). Cultures of the gonads and genitalia were made from the material removed at gonadectomy. A small skin biopsy was taken from the site of the abdominal incision. The histological preparations of the gonads and genital ducts were made following fixation in $10 \%$ formol saline. The sections were stained with haematoxylin and eosin.

\section{Red setter}

\section{Observations}

This animal (H77-563) was 8 months old, and was referred because of short bouts of urinary retention. It had been considered to be a male dog by the owner although the prepuce was very rudimentary, with an opening, resembling a vulva, just below the ischial arch. No penis or clitoris could be recognized by sight or feel. A very rudimentary scrotal sac was present but it contained no palpable gonads. The animal was otherwise healthy, with the exception of some opacity of the lens of the eyes: in a breeder's opinion it had a 'female head conformation'. At gonadectomy an apparently normal female genital tract was found, with two ovaries of normal size for the age of the animal. The body of the uterus was removed from the cervical end, but it was not possible to establish the existence of a cervix. Both ovaries were removed. The recovery of the dog was uneventful. 
Table 1 gives the cytogenetic analysis of tissues from the Red setter. It shows a $78, \mathrm{XX} / 79, \mathrm{XXY}$ mosaicism of all the tissues which were examined; all were from primary cultures of less than 5 days and contained a low proportion (14\% or less) of XXY cells. In the right and left gonads the proportions were only $4 \%$ and $11 \%$ respectively: Pl. 1, Fig. 1 shows the karyotype of the $79, \mathrm{XXY}$ cells. Both gonads had an apparently normal ovarian cortex with numerous follicles containing ova (Pl. 1, Fig. 2); in the medulla there was evidence of a rudimentary development of tubules, which is a testicular feature (Pl. 1, Fig. 3). No remnants of Wolffian ducts were seen in this animal.

Table 1. Chromosome complement of tissues from the Red setter

\begin{tabular}{lcccc}
\hline & \multicolumn{4}{c}{ Numbers of cells } \\
\cline { 2 - 5 } \multicolumn{1}{c}{ Tissue } & Total & XX & XXY & $\%$ XXY \\
\hline Blood lymphocytes & 40 & 36 & 4 & 10 \\
Uterus & 29 & 25 & 4 & 14 \\
Right gonad & 50 & 48 & 2 & 4 \\
Left gonad & 45 & 40 & 5 & 11 \\
\hline
\end{tabular}

\section{Cocker spaniel}

The spaniel (H77-1168) was seen at about 1 year of age; it was a rare liver-roan in colour. The owner hoped to be able to show and breed from this dog, but was concerned because the penis tended to protrude from the prepuce, and the tip was deformed due to a persistent frenulum. The prepuce was normally formed, if slightly small, and the rudimentary scrotal sac contained a palpable right gonad. The frenulum of the penis was severed, but as this failed to allow retraction of the penis into the prepuce it was necessary to carry out a partial amputation. At laparotomy the left gonad was present in the abdomen and the right was in the scrotum. Bilateral epididymides, vasa deferentia, seminal vesicles and oviducts were found; there was a well developed uterus. The gonads, uterus and duct systems were all removed.

Table 2 gives the cytogenetic analysis of tissues from this animal. The majority of the cells (about 60\%) had the normal female karyotype. The remainder had a sex chromosome complement of two $\mathrm{X}$ chromosomes associated either with a questionable $\mathrm{Y}$ chromosome (which often lay close to an autosome: Pl. 2, Fig. 4) or with one or more small 'fragments' of chromatin

\section{EXPLANATION OF PLATES}

\section{PLATE 1}

Fig. 1. Karyotype of a $79 \times X Y$ cells from the Red setter.

Fig. 2. Ovarian cortex from the right gonad of the Red setter, showing ova in ripening follicles. $\times 28.5$.

Fig. 3. Medullary region of the right gonad showing rudimentary development of tubules. $\times 84$.

\section{PLATE 2}

Fig. 4. Karyotype of a cell from the Cocker spaniel. The fragment which may be a Y chromosome is arrowed.

Fig. 5. Chromosome spread from the Cocker spaniel, showing 'fragments' of chromatin (arrowed).

Fig. 6. Section of the right oviduct and vas deferens of the Cocker spaniel. $\times 14$.

Fig. 7. Section of the left testis from the Cocker spaniel. $\times 84$.

Fig. 8. Section of the left testis from the Cocker spaniel, showing a dark cell (arrowed) which may be a primitive spermatogonium. $\times 84$. 


\section{PLATE 1}

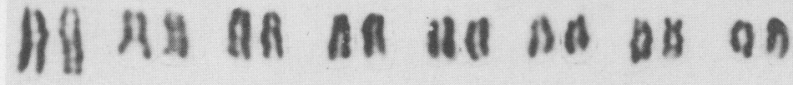

\section{An He HB Ha na an on na}

ni) a chon an ba na na 110 “ハ

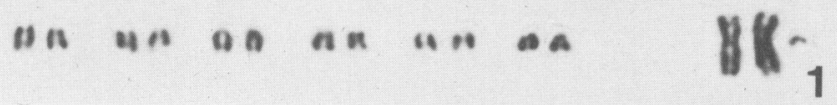
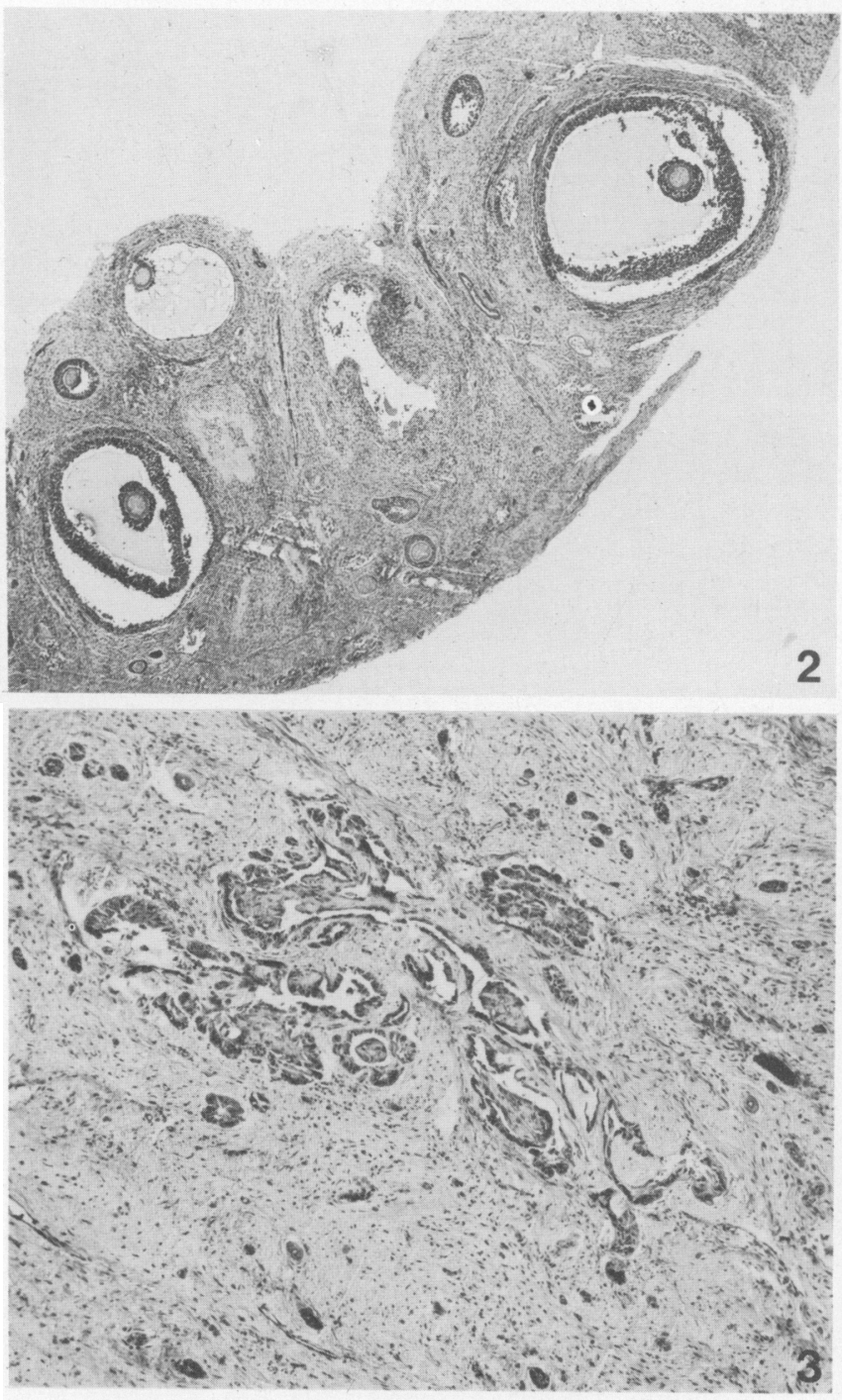
PLATE 2

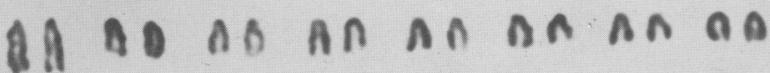

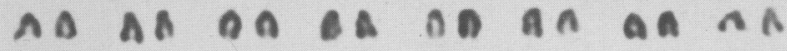

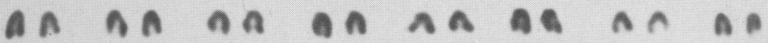

r

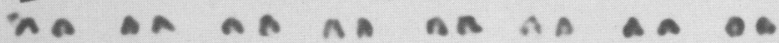

OP A a n a a n a

$\mathbb{X}_{4}$
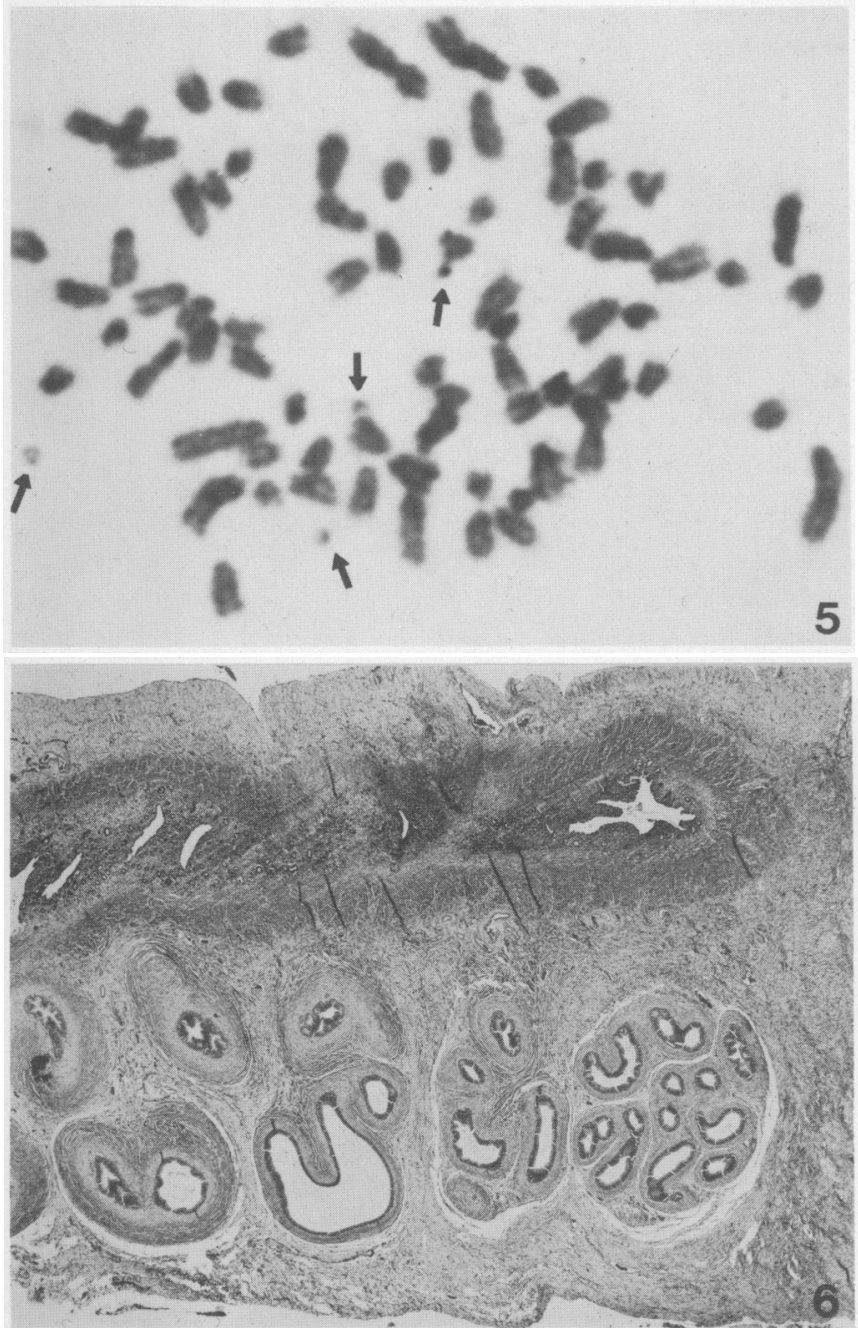

5

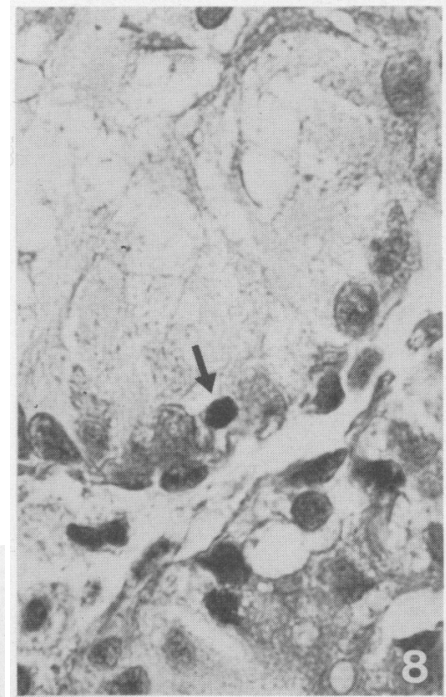


(PI. 2, Fig. 5) which were smaller than a Y chromosome. In one cell both the questionable Y chromosome and a 'fragment' were seen. Seven of the XXY cells had a complement of 79 chromosomes: 4 came from the blood and 1 each from the uterus and right and left gonads. The others were hypomodal. In a few cells the morphology or attitude of the chromosomes made their identity uncertain. The proportion of cells with questionable $Y$ chromosomes and 'fragments' was 32 and $23 \%$ in right and left gonads respectively. These cells grew slowly in culture: usable preparations from the right gonad were made on the 21 st and 24 th days and from the left gonad on the 13 th and 27 th days. Transverse sections of the oviduct and vas deferens from the right gonad are shown in Pl. 2, Fig. 6 and the histology of the left testis in Pl. 2, Fig. 7. The testes consisted of Leydig cells and seminiferous tubules lined with Sertoli cells. Germ cells were not positively identified. There was a rare occurrence in some tubules of cells which may have been primitive spermatogonia (Pl. 2, Fig. 8); none which might have been germ cells in a more advanced stage was found. The Müllerian structures on the left side were less developed than those on the right.

Table 2. Chromosome complement of tissues from the Cocker spaniel

\begin{tabular}{|c|c|c|c|c|c|c|}
\hline \multirow[b]{2}{*}{ Tissue } & \multicolumn{6}{|c|}{ Numbers of cells } \\
\hline & Total & $\mathrm{XX}$ & With ?Y & $\begin{array}{c}\text { With } \\
\text { 'fragment' }\end{array}$ & $\begin{array}{c}\text { With } \\
\text { unidentified } \\
\text { sex } \\
\text { chromosomes }\end{array}$ & $\begin{array}{l}\% \text { cells } \\
\text { with ?Y } \\
\text { or } \\
\text { 'fragment' }\end{array}$ \\
\hline Blood lymphocytes & 25 & 12 & 9 & 0 & 4 & 36 \\
\hline Skin & 7 & 6 & 0 & 0 & 1 & 0 \\
\hline Uterus & 57 & 44 & 6 & $6^{*}$ & 2 & 19 \\
\hline Right gonad & 38 & 25 & 10 & 2 & 1 & 32 \\
\hline Left gonad & 13 & 9 & 2 & 1 & 1 & 23 \\
\hline
\end{tabular}

* One cell contained both ?Y and a 'fragment'.

\section{Discussion}

Both the dogs had mosaicism of other tissues as well as of the reticulo-endothelial system. Only the latter is affected by chimaerism of the freemartin type, which is caused by placental anastomosis. The mosaicism was therefore a primary one in both cases. The most likely origin of the fault is an XXY zygote which underwent non-disjunction during cleavage to produce the two cell lines which were subsequently found.

Two particular points of interest arise: first, the possible importance of the proportion of $Y$ bearing cells in the gonadal soma for the determination of the gonadal sex; and second, the possibility of the involvement of a genetic factor. The suggestion of Ford (1970) that there may be a threshold proportion of Y-bearing cells in the gonadal soma which specify a testis has been discussed with reference to cattle (Bos taurus: Dain \& Bridge, 1978). The proportions of male cells in the gonads of these two dogs, if they reflect those of the embryo stage, seem to support the possibility that a threshold number of Y-bearing cells (somewhere in the region of 20-25\%) is sufficient to determine the formation of a testis. In the Red setter, the proportion of 4 and $11 \%$ of male cells in right and left gonads respectively was so low that an apparently normal ovarian cortex with ova in ripening follicles could form. Testicular features were limited to a minor development of tubules in the medullary region, which may, nevertheless, have been sufficient to promote the elongation of the genital sinus into an elongated urethra. Jost, Perchellet, Prépin \& Vigier (1975) have shown that this is the first feature of male differentiation to take place in cattle in the presence of a testis. In the Red setter (as in the mosaic calf described by Dain \& Bridge, 1978), no other masculinizing effect was seen; the Wolffian ducts had degenerated, as 
they do in the normal female in the absence of androgens, while the Müllerian structures had developed normally as far as could be seen at gonadectomy. It therefore seems that the testicular development was insufficient to produce an anti-Müllerian effect. The same situation arose in a Cocker spaniel described by Walker (1961) except that in that animal tubules, interstitial tissue and clitoris were more developed.

The case of the Cocker spaniel raises the question of the mechanism of XX sex reversal. The chromosomal anomalies, which may or may not include material from a Y chromosome, could explain the presence of testes. The well developed external genitalia and Wolffian derivatives suggest that the Leydig tissue produced adequate androgens at the critical stage of organogenesis. It is more difficult to account for the presence of the uterus and oviducts. AntiMüllerian action is associated with testis tubules lined with Sertoli cells (Donahoe, Ito, Price \& Hendren, 1977), as they were in this animal, and it is usual for the testis in Klinefelter's syndrome, even in XX/XXY mixoploidy, to have an effective anti-Müllerian action. McKusick (1975) lists the persistence of Müllerian derivatives among the recessive lesions in man. It is therefore worth considering the possibility that the $\mathrm{XX} / \mathrm{XXY}$ mosaicism even if it exists may not provide the whole explanation of the condition: additional genetic factors may have been involved. There have been a number of reports of intersexuality in Cocker spaniels: 4 with an XX genotype have been reviewed previously (Dain, 1974). While it is possible that they had undetected chromosomal anomalies it may also be that such visible lesions lie at one end of a range of cytogenetic disturbances while undetected, but nevertheless effective genetic rearrangements lie at the other. Winsor, Ferguson-Smith \& Shire (1978) have suggested that the sex reversal factor $(\mathrm{Sxr})$ in mice, which acts as an autosomal dominant, may be a chromosomal rearrangement involving a small, undetected Y-translocation or insertion. They also identified small fragments of chromatin in cells from animals carrying the Sxr factor. Winsor et al. (1978) suggest that this may be $\mathrm{Y}$ chromosome material which is most often inserted in an autosome, but which is occasionally unstable in meiotic division. There is no evidence of the origin of the 'fragments' in our Cocker spaniel. They may have had a Y-chromosomal origin, but this need not have been the case. They may merely indicate a fragility in the genome and this may underlie the genetic lesion which induced the masculinizing effect.

We thank Mr J. G. Jarvis for the histological preparations and Mr A. L. Gallup for the photography. We gratefully acknowledge the help of $\mathrm{Dr}$ A. R. Jennings in examining the histology of the abnormal ovaries and of Professor I. B. Fritz in the examination of the testes.

\section{References}

Basrur, P.K. \& Gilman, J.P.W. (1964) Blood culture method for the study of bovine chromosomes. Nature, Lond. 204, 1335.

Dain, A.R. (1974) Intersexuality in a Cocker spaniel dog. J. Reprod. Fert. 39, 365-371.

Dain, A.R. \& Bridge, P.S. (1978) A chimaeric calf with $\mathrm{XX} / \mathrm{XXY}$ mosaicism and intersexuality. J. Reprod. Fert. 54, 197-201.

Donahoe, P.K., Ito, Y., Price, J.M. \& Hendren, W.H. (1977) Müllerian inhibiting substance activity in bovine fetal newborn and prepubertal testes. Biol. Reprod. 16, 238-243.

Ford, C.E. (1970) The cytogenetics of the male germ cells and the testis in mammals. In The Human Testis, pp. 139-147. Eds E. Rosenberg \& C. A. Poulson. Plenum Press, New York.
Jost, A., Perchellet, J.P., Prépin, J. \& Vigier, B. (1975) The prenatal development of bovine freemartins. In Intersexuality in the Animal Kingdom, pp. 392-406. Ed. R. Reinboth. Springer Verlag, Heidelberg.

McKusick, V.A. (1975) Catalogue Number 26155. In Mendelian Inheritance in Man, 4th edn. Johns Hopkins University Press, Baltimore.

Tucker, E.M., Dain, A.R. \& Moor, R.H. (1978) Sex chromosome chimaerism and the transmission of blood group genes by tetraparental rams. J. Reprod. Fert. 54, 77-83.

Walker, R.G. (1961) Hermaphroditism in a bitch. A case report. Vet. Rec. 73, 670-671.

Winsor, E.J.T., Ferguson-Smith, M.A. \& Shire, J.O.M. (1978) Meiotic studies in mice carrying the sex reversal (Sxr) factor. Cytogenet. Cell Genet. 21, 1118. 